be justified. The alternative of dialling the computer from the bedside is not practical at present in most British hospitals. In any event the ECG report would normally be printed centrally in the hospital and should be checked before being returned to the ward.

\section{WIDER USE OF COMPUTER}

With the introduction of health centres there is an increasing need for recording facilities within each centre. We are currently co-operating with two health centres. Each has a data acquisition trolley located permanently within the centre. In one the nursing staff make the ECG recordings, which are transported daily to the Royal Infirmary by van. At the same time interpretations of the previous day's recordings are returned. In the other health centre a technician from the Royal Infirmary visits the centre at least once a week to make the recordings.

In neither centre has the need for an emergency report been clearly shown. The vast majority of patients who require an ECG as part of their investigation can either wait a few days for an ECG or have an immediate recording and receive the interpretation one or two days later. If the general practitioner thinks that an emergency report is needed then the patient can be sent to hospital from the second health centre, while in the first centre the ECG can be recorded and one of the two trained GPs can scan the ECG to look for acute changes and make any necessary therapeutic decision.

There seems to be a need for a portable multichannel electrocardiograph with magnetic tape-recording or telephone facilities for transmitting the ECG to the computer centre. In this way one technician could provide a half-day session in 10 health centres each week. In our experience 20 ECG recordings per week per health centre is a reasonable number to expect, so one technician could cope quite easily with this work load. Installing an electrocardiograph and telephone transmission with printout facilities in each health centre is not really justified. It would cost about $£ 7000$ per centre. On the other hand, one portable recording system taken to each health centre for one half-day session a week would cost perhaps $£ 5000$ and minimise maintenance costs. Furthermore, the equivalent of only one trained technician would be required whereas every health centre would have to employ a competent technician if the other approach were adopted.

Any spare time which the computer has will depend on the number of hospitals or health centres which are directly or indirectly linked to the system. We are currently investigating the possibility of using spare capacity for screening employees at a small charge. This may be one way of helping to meet the severe financial problems which the Health Service is experiencing.

All those engaged in ECG interpretation by computer acknowledge that ECGs should be quickly scrutinised by a physician or cardiologist before being distributed to wards and clinics. The computer interpretation, however, enables the ECGs to be checked much faster (up to five times faster than conventional reporting), while observer variation is minimised. It is quite feasible for well-trained physiological measurement technicians to scrutinise computer output to determine whether any tracings should be referred to a cardiologist for checking or whether they could be distributed immediately. In this way the work load on physicians would be kept to an absolute minimum.

This work was carried out with the aid of grants from the Scottish Home and Health Department. The authors would like to acknowledge the co-operation of the general practitioners in Woodside and Rutherglen health centres, Glasgow.

\section{References}

${ }^{1}$ Macfarlane, P W, Cardiovascular Research, 1969, 3, 510.

2 Watts, M P, and Macfarlane, P W, Medical and Biological Engineering, in press.

${ }^{3}$ Macfarlane, P W, et al, British fournal of Clinical Equipment, 1976, 1, 61.

${ }^{4}$ British Medical fournal, 1974, 3, 702.

(Accepted 2 December 1976)

\title{
Perinatal deaths: analysis by clinical cause to assess value of induction of labour
}

\author{
MARGARET B McNAY, GILLIAN M McILWAINE， P W HOWIE， M C MACNAUGHTON
}

British Medical fournal, 1977, 1, 347-350

\section{Summary}

Over the 10 years 1966-75 the rate of induction of labour in the Glasgow Royal Maternity Hospital has increased from $16 \cdot 3 \%$ to $35.6 \%$ of all births. During the same

\footnotetext{
Social, Paediatric and Obstetric Research Unit, University of Glasgow

MARGARET B MCNAY, MB, MRCOG, research fellow

Greater Glasgow Health Board

GILLIAN M MCILWAINE, MD, PHD, fellow in community medicine

Department of Obstetrics and Gynaecology, Royal Maternity Hospital, Glasgow G4 ONA

$P$ W HOWIE, MD, MRCOG, senior lecturer

M C MACNAUGHTON, MD, FRCOG, Muirhead professor of obstetrics and gynaecology
}

period perinatal mortality fell from 33 to 22 per 1000 , mainly because of significantly fewer deaths due to antepartum haemorrhage; trauma; maternal disease; and unknown causes in mature babies. The reduction in the number of deaths of unknown causes in mature fetuses was achieved by preventing deaths occurring after 40 weeks and was recorded in all age and parity groups. The results suggested that increased use of induction of labour has contributed to the improved perinatal mortality rate.

\section{Introduction}

Walker ${ }^{1}$ emphasised the importance of postmaturity as a causal factor in perinatal death, and his finding was confirmed in the first British Perinatal Mortality Survey. ${ }^{2}$ Different studies have shown that better results are produced when labour is routinely induced at 41 weeks than when the pregnancy is allowed to continue. $^{34}$ Baird $^{5}$ claimed that the risks of prolonged pregnancies were greatest in primigravidae aged over 30 years and 
that more frequent use of induction dramatically improved results in this group. More efficient induction methods have encouraged many units to increase sharply their induction rates, but it has not been established that this has reduced perinatal mortality. ${ }^{6}$

Using the classification of perinatal deaths by clinical cause introduced by Baird et $a l^{7}$ in 1954, a study in Glasgow in 1970 showed that deaths from unknown causes in mature babies contributed 3 deaths per 1000 births to the perinatal mortality rate. ${ }^{8}$ Many of these deaths were stillbirths occurring after term and seemed potentially preventable by timely induction of labour. Between 1971 and 1975 the incidence of induction of labour increased steadily in the Glasgow Royal Maternity Hospital, and we report here on its effect on perinatal mortality.

\section{Patients and methods}

We studied the case sheets of all patients delivered in the Glasgow Royal Maternity Hospital and associated Ross Hospital during 1966-75, and recorded the information on Cope-Chat curds. We analysed only single births in considering whether induction had had any effect in reducing the number of deaths due to certain causes.

Induction of labour was defined as uterine stimulation with oxytocin, prostaglandins or artificial rupture of the membranes in patients in whom spontaneous labour had not occured.

We classified the perinatal deaths by cause ${ }^{7}$ as follows: (a) premature, cause unknown-birth weight $\leqslant 2500 \mathrm{~g}$; (b) mature, cause unknown-birth weight $>2500 \mathrm{~g}$; (c) trauma; $(d)$ toxaemia; $(e)$ antepartum haemorrhage; $(f)$ maternal disease; $(g)$ fetal deformity; (h) other causes (infection, $\mathrm{Rh}$ factor, etc).

These eight causes of death fall into two broad categories-the obstetrical causes (mature, unknown; trauma; toxaemia; maternal disease; and $\mathrm{Rh}$ incompatibility), which may be reduced by improved obstetrical care, and the environmental causes (premature, unknown antepartum haemorrhage; and fetal deformity) which are related to the effects of an unfavourable environment on a mother's reproductive function. Statistical interpretations were based on standard errors and $\chi^{2}$ tests.

\section{Results}

DELIVERY, INDUCTION, AND CAESAREAN SECTION RATES

We compared delivery, induction, and caesarean section rates in two five-year periods: $1966-70$, when there were 28663 single births, and 1971-5, when there were 19849 single births. The induction rate rose from $19.2 \%$ in $1966-70$ to $35.6 \%$ in $1971-5$, during which time the caesarean section rate rose from $7 \cdot 8 \%$ to $12 \cdot 8 \%$ (table I).

\section{PERINATAL MORTALITY}

The perinatal mortality rate fell from 33 per 1000 to 22 per 1000 over the 10 years 1966-75. The deaths are classified by clinical cause in table II. Comparing the five-year periods $1966-70$ and 1971-5, the overall perinatal mortality rate fell from 27.5 to 22.3 per 1000 $(P<0.05)$. Deaths from unknown causes in mature fetuses fell from 2.4 to 0.7 per $1000(P<0.001)$, deaths due to antepartum haemorrhage

TABLE I-Total number of singleton deliveries and induction and caesarean section rates in 1966-75 in Glasgow Royal Maternity Hospital and associated hospitals

\begin{tabular}{|c|c|c|c|c|c|c|c|c|c|c|c|c|}
\hline & & & 1966 & 1967 & 1968 & 1969 & 1970 & 1971 & 1972 & 1973 & 1974 & 1975 \\
\hline $\begin{array}{l}\text { Total No of singleton deliveries } \\
\text { Induction rate }(\%) \\
\text { Caesarean section rate }(\%)\end{array}$ & 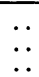 & 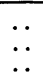 & $\begin{array}{r}6106 \\
16 \cdot 3 \\
7 \cdot 7\end{array}$ & $\begin{array}{r}6108 \\
16 \cdot 9 \\
7 \cdot 1\end{array}$ & $\begin{array}{r}5930 \\
17 \cdot 3 \\
7 \cdot 4\end{array}$ & $\begin{array}{r}5523 \\
22 \cdot 2 \\
8 \cdot 4\end{array}$ & $\begin{array}{r}4996 \\
31 \cdot 7 \\
8 \cdot 3\end{array}$ & $\begin{array}{r}4736 \\
33 \cdot 7 \\
8 \cdot 5\end{array}$ & $\begin{array}{l}4067 \\
32 \cdot 8 \\
13 \cdot 6\end{array}$ & $\begin{array}{l}3687 \\
36 \cdot 3 \\
13 \cdot 6\end{array}$ & $\begin{array}{r}3501 \\
40 \cdot 6 \\
15 \cdot 6\end{array}$ & $\begin{array}{r}3858 \\
35 \cdot 6 \\
13 \cdot 9\end{array}$ \\
\hline
\end{tabular}

TABLE II-Classification by clinical cause of perinatal deaths (singleton births only) 1966-75 at Glasgow Royal Maternity Hospital and associated hospitals. Rate is per 1000 singleton births

\begin{tabular}{|c|c|c|c|c|c|c|c|c|c|c|c|c|c|c|c|c|c|c|c|c|c|}
\hline & \multicolumn{2}{|c|}{1966} & \multicolumn{2}{|c|}{1967} & \multicolumn{2}{|c|}{1968} & \multicolumn{2}{|c|}{1969} & \multicolumn{2}{|c|}{1970} & \multicolumn{2}{|c|}{1971} & \multicolumn{2}{|c|}{1972} & \multicolumn{2}{|c|}{1973} & \multicolumn{2}{|c|}{1974} & \multicolumn{2}{|c|}{1975} & \multirow{2}{*}{$\begin{array}{c}\text { Comparison } \\
\text { of } 1966-70 \\
\text { and } 1971-5 \\
(P \text { value })\end{array}$} \\
\hline & No & Rate & No & Rate & No & Rate & No & Rate & No & Rate & No & Rate & No & Rate & No & Rate & No & Rate & No & Rate & \\
\hline 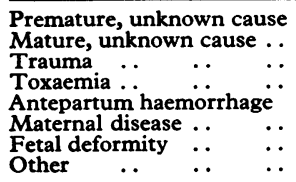 & $\begin{array}{r}39 \\
13 \\
15 \\
14 \\
57 \\
7 \\
42 \\
20\end{array}$ & $\begin{array}{l}6 \cdot 4 \\
2 \cdot 4 \\
2 \cdot 5 \\
2 \cdot 2 \\
9 \cdot 3 \\
1 \cdot 2 \\
6 \cdot 9 \\
3 \cdot 3\end{array}$ & $\begin{array}{r}35 \\
23 \\
12 \\
14 \\
36 \\
5 \\
33 \\
18\end{array}$ & $\begin{array}{l}5 \cdot 7 \\
3 \cdot 8 \\
2 \cdot 0 \\
2 \cdot 3 \\
5 \cdot 9 \\
0 \cdot 8 \\
5 \cdot 4 \\
3 \cdot 0\end{array}$ & $\begin{array}{l}29 \\
16 \\
11 \\
11 \\
41 \\
3 \\
34 \\
18\end{array}$ & $\begin{array}{l}4.9 \\
2.7 \\
1.9 \\
1.9 \\
6.9 \\
0.5 \\
5.7 \\
3.0\end{array}$ & $\begin{array}{r}29 \\
13 \\
7 \\
8 \\
27 \\
4 \\
25 \\
10\end{array}$ & $\begin{array}{l}5 \cdot 3 \\
2 \cdot 4 \\
1.3 \\
1.5 \\
4 \cdot 9 \\
0 \cdot 7 \\
4 \cdot 5 \\
1 \cdot 8\end{array}$ & $\begin{array}{r}27 \\
5 \\
16 \\
14 \\
28 \\
2 \\
26 \\
10\end{array}$ & $\begin{array}{l}5 \cdot 4 \\
1.0 \\
3 \cdot 2 \\
2 \cdot 8 \\
5 \cdot 6 \\
0.4 \\
5 \cdot 2 \\
2 \cdot 0\end{array}$ & $\begin{array}{r}30 \\
4 \\
12 \\
15 \\
12 \\
1 \\
24 \\
18\end{array}$ & $\begin{array}{l}6 \cdot 3 \\
0 \cdot 8 \\
2 \cdot 5 \\
3 \cdot 2 \\
2 \cdot 5 \\
0 \cdot 2 \\
5 \cdot 1 \\
3 \cdot 8\end{array}$ & $\begin{array}{r}26 \\
3 \\
5 \\
18 \\
17 \\
1 \\
32 \\
12\end{array}$ & $\begin{array}{l}6 \cdot 4 \\
0 \cdot 7 \\
1 \cdot 2 \\
4 \cdot 4 \\
4 \cdot 2 \\
0 \cdot 3 \\
7 \cdot 8 \\
3 \cdot 0\end{array}$ & $\begin{array}{r}17 \\
4 \\
2 \\
7 \\
23 \\
2 \\
23 \\
3\end{array}$ & $\begin{array}{l}4 \cdot 6 \\
1.1 \\
0.5 \\
1.9 \\
6.2 \\
0.5 \\
6.2 \\
0.8\end{array}$ & $\begin{array}{r}11 \\
2 \\
0 \\
8 \\
18 \\
0 \\
18 \\
3\end{array}$ & $\begin{array}{l}3 \cdot 1 \\
0.6 \\
0 \cdot 0 \\
2 \cdot 3 \\
5 \cdot 1 \\
0 \cdot 0 \\
5 \cdot 1 \\
0.9\end{array}$ & $\begin{array}{r}26 \\
2 \\
4 \\
8 \\
18 \\
2 \\
24 \\
4\end{array}$ & $\begin{array}{l}6.7 \\
0.5 \\
1.0 \\
2.1 \\
4.7 \\
0.5 \\
6.2 \\
1.0\end{array}$ & $\begin{array}{c}\text { NS } \\
<0.001 \\
<0.05 \\
\text { NS } \\
<0.01 \\
<0.05 \\
\text { NS } \\
\text { NS }\end{array}$ \\
\hline Total & 207 & 33.9 & 176 & $28 \cdot 8$ & 163 & $27 \cdot 5$ & 123 & $22 \cdot 3$ & 128 & $25 \cdot 6$ & 113 & 23.9 & 114 & $28 \cdot 0$ & 81 & 21.9 & 60 & $\mid 17 \cdot 1$ & 88 & $22 \cdot 8$ & $<0.05$ \\
\hline
\end{tabular}

NS $=$ Not significant

TABLE III-Distribution of population, induction rate, and numbers of deaths of unknown cause in mature fetuses according to age and parity of mother. Rate is per 1000 single births

\begin{tabular}{|c|c|c|c|c|c|c|c|c|c|}
\hline & \multicolumn{2}{|c|}{$\%$ Distribution } & \multicolumn{2}{|c|}{ Induction rate $(\%)$} & \multicolumn{4}{|c|}{ MU deaths } & \multirow{3}{*}{$\begin{array}{l}\text { Significance of fall } \\
\text { in No of MU deaths }\end{array}$} \\
\hline & \multirow{2}{*}{$1966-70$} & \multirow{2}{*}{$1971-5$} & \multirow{2}{*}{$1966-70$} & \multirow{2}{*}{$1971-5$} & \multicolumn{2}{|c|}{$1966-70$} & \multicolumn{2}{|c|}{$1971-5$} & \\
\hline & & & & & No & Rate & No & Rate & \\
\hline \multirow{2}{*}{$\begin{array}{c}\text { Age (years) } \\
<20 \\
20-24 \\
25-29 \\
30-34 \\
\geqslant 35 \\
\text { Parity } \\
0 \\
1 \\
2 \\
3 \\
\geqslant 4\end{array}$} & $\begin{array}{l}11.5 \\
33.6 \\
28.3 \\
15.9 \\
10.7\end{array}$ & $\begin{array}{r}13.2 \\
34.0 \\
29.8 \\
14.5 \\
8.5\end{array}$ & $\begin{array}{l}16.6 \\
17.4 \\
19.8 \\
19.9 \\
21.4\end{array}$ & $\begin{array}{l}32 \cdot 9 \\
34 \cdot 2 \\
37 \cdot 7 \\
38 \cdot 2 \\
33 \cdot 2\end{array}$ & $\begin{array}{r}4 \\
20 \\
22 \\
15 \\
9\end{array}$ & $\begin{array}{l}1 \cdot 2 \\
2 \cdot 1 \\
2 \cdot 7 \\
3.3 \\
2 \cdot 9\end{array}$ & $\begin{array}{l}2 \\
2 \\
4 \\
4 \\
3\end{array}$ & $\begin{array}{l}0.7 \\
0.3 \\
0.7 \\
1.7 \\
1.0\end{array}$ & $\begin{array}{c}\text { NS } \\
<0.01 \\
<0.01 \\
\text { NS } \\
\text { NS }\end{array}$ \\
\hline & $\begin{array}{r}38 \cdot 8 \\
26.8 \\
14.9 \\
8 \cdot 2 \\
11 \cdot 6\end{array}$ & $\begin{array}{r}40.9 \\
29.6 \\
14.9 \\
7.2 \\
7.4\end{array}$ & $\begin{array}{l}20 \cdot 5 \\
16 \cdot 5 \\
18 \cdot 6 \\
20 \cdot 7 \\
20 \cdot 3\end{array}$ & $\begin{array}{l}39 \cdot 3 \\
32 \cdot 7 \\
33 \cdot 3 \\
33 \cdot 9 \\
33 \cdot 3\end{array}$ & $\begin{array}{r}30 \\
12 \\
8 \\
5 \\
15\end{array}$ & $\begin{array}{l}2.7 \\
1.5 \\
1.9 \\
2.1 \\
4.4\end{array}$ & $\begin{array}{l}7 \\
4 \\
1 \\
2 \\
1\end{array}$ & $\begin{array}{l}1.0 \\
0.5 \\
0.3 \\
1.4 \\
0.7\end{array}$ & $\begin{array}{c}<0.01 \\
\text { NS } \\
\text { NS } \\
\text { NS } \\
<0.05\end{array}$ \\
\hline
\end{tabular}

MU = Mature, unknown cause. $\quad$ NS $=$ Not significant. 
from 6.5 to 4.3 per $1000(P<0.01)$, deaths due to trauma from 2.1 to 1.1 per $1000(P<0.05)$, and deaths due to maternal disease from 0.7 to 0.3 per $1000(P<0.05)$. There were no significant falls in the number of deaths due to unknown causes in premature fetuses, toxaemia, fetal deformity, or other causes.

\section{DEATHS OF UNKNOWN CAUSE IN MATURE FETUSES}

Cross-tabulation of age and parity in the first five-year period showed that the greatest number of these deaths from unknown causes occurred in primigravidae aged 20-29 years (23 deaths) and in those over the age of 30 having their fifth or subsequent child (13 deaths). In 1971-5 perinatal mortality in this category improved at all ages and parities (table III), but the improvement was greatest in primigravidae and in those aged $20-24$ and $25-29$ ( $P<0.01$ in all cases). Similarly, a reduction in the number of deaths from unknown causes in mature fetuses occurred throughout each social class and height grouping. From 1966-70 to $1971-5$ the number of these deaths occurring before labour fell from $1 \cdot 2$ to 0.4 per 1000 , those in labour from 0.7 to 0.2 per 1000 , and those in the neonatal period from 0.6 to 0.2 per 1000 . The number of these deaths occurring at 40 weeks or later fell from 1.7 to 0.3 per $1000(P<0.01)$, but those occurring before 40 weeks fell only from 0.7 to 0.5 per 1000 (table IV).

TABLE IV-Social class and height of mother, time of death, and length of gestation in deaths of unknown cause in mature fetuses. Rate is per 1000 single births

\begin{tabular}{|c|c|c|c|c|c|c|}
\hline & & \multicolumn{2}{|c|}{$1966-70$} & \multicolumn{2}{|c|}{$1971-5$} \\
\hline & & & No & Rate & No & Rate \\
\hline \multicolumn{7}{|l|}{ Social class: } \\
\hline I and II & .. & .. & 6 & $0 \cdot 2$ & 0 & 0 \\
\hline & . & . & 25 & 0.9 & 6 & 0.3 \\
\hline IV and V & .. & . & 29 & 1.0 & 8 & \\
\hline \multicolumn{7}{|c|}{$\begin{array}{l}\text { Not stated } \\
\text { Height }(\mathrm{cm}):\end{array}$} \\
\hline-147 & .. & $\ldots$ & 2 & $0 \cdot 1$ & 1 & $0 \cdot 1$ \\
\hline $148-152$ & . & .. & 15 & 0.5 & 2 & $0 \cdot \overline{1}$ \\
\hline $153-157$ & $\ldots$ & $\ldots$ & 11 & $0 \cdot 4$ & 4 & 0.2 \\
\hline $158-163$ & $\therefore$ & .. & 24 & 0.8 & 4 & 0.2 \\
\hline $164-168$ & . & . & 5 & $0 \cdot 2$ & 3 & 0.2 \\
\hline$\geqslant 169$ & $\cdots$ & $\cdots$ & 1 & 0.03 & 0 & \\
\hline $\begin{array}{c}\text { Not stated } \\
\text { Time of death }\end{array}$ & \multicolumn{6}{|c|}{ Time of death: } \\
\hline Before labo & & $\ldots$ & 35 & $1 \cdot 2$ & 8 & 0.4 \\
\hline In labour & & $\ldots$ & 19 & $0 . \overline{7}$ & 4 & $0 \cdot 2$ \\
\hline Neonatally & . & 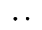 & 16 & 0.6 & 3 & 0.2 \\
\hline \multirow{2}{*}{\multicolumn{7}{|c|}{ Length of gestation }} \\
\hline & & & & & & \\
\hline$<40 \quad \ldots$ & .. & .. & 20 & 0.7 & 10 & 0.5 \\
\hline$\geq \mathbf{4 0}$ & . & . & 48 & 1.7 & 5 & 0.3 \\
\hline
\end{tabular}

\section{TRAUMA}

In comparing 1966-70 with 1971-5, the improvement in perinatal mortality rate ascribed to trauma was due to fewer deaths from cord accidents $(0.8$ to 0.3 per 1000$)$ and obstructed or prolonged labour $(0.4$ to 0.0 per 1000$)$. There were no significant changes in the numbers of deaths due to breech delivery $(0.4$ to 0.3 per 1000$)$, traumatic delivery $(0.3$ to 0.4 per 1000$)$, or prolonged fetal distress $(0.2$ to 0.2 per 1000).

\section{POPULATION CHANGES}

The characteristics of the populations in 1966-70 and 1971-5 were compared and showed several changes.

Birth rate-The birth rate in the city of Glasgow fell from 20.2 per 1000 population in 1966 to 12.9 in 1975.

Age and parity-From 1966-70 to $1971-5$ there was a slight reduction in maternal age, with an increase in the proportion of teenage mothers and a fall in the proportion of women aged 35 years or over (table III). The percentage of women having their fourth or subsequent child fell from $19 \cdot 8 \%$ to $14 \cdot 6 \%$. Cross-tabulation of age and parity in the two periods showed a reduction in 1970-5 in the percentage of births to women of all parities aged 30 years and over. Among primigravidae aged 20-29 years the percentage of births in 1966-70 was $26 \%$ and in $1971-527 \%$.

Social class, height, and marital status-Information on these factors was incomplete for the first five-year period. A comparison between 1971 and 1974 was made and showed only minor differences. In $197133 \%$ of the patients belonged to social class IV or V (RegistrarGeneral's classification), while in 1974 the figure was $32 \%$. In 1971 $38 \%$ of patients were less than $157 \mathrm{~cm}$ tall, and this figure rose to $41 \%$ in 1974 . In $19717 \%$ of the pregnancies were illegitimate. This figure rose to $9 \%$ in 1974 .

\section{Discussion}

Our most striking finding was the sharp fall in the number of perinatal deaths classified as "mature, cause unknown." These deaths occur for no apparent reason in infants weighing over $2500 \mathrm{~g}$ and are commonly attributed to placental insufficiency or prolonged pregnancy. Since a widespread policy of induction of labour will exert its major effect on perinatal deaths late in pregnancy, its value should be principally assessed by its influence on this group of deaths. The reduction in the number of deaths of unknown cause in mature fetuses in this series could be explained in two ways: either there was a major change in the obstetric population or there was an improvement in obstetric management.

Several factors strongly suggest that a change in the obstetric population was not the main reason for the better results in the mature, cause unknown category. The number of these deaths fell in all age, parity, height, and social class groups, which would not have happened if population change had been the major factor. For example, in primigravidae aged 20-29, whose proportion was unchanged in the two five-year periods, the number of deaths from unknown causes in mature fetuses fell from 20 to 4 . Taking into account the overall fall in the total number of deliveries, we would have expected 17 deaths in the second five-year period. Thus 13 lives were saved in a group not generally regarded as being at risk. There were no significant changes in the numbers of deaths due to prematurity (cause unknown) and fetal abnormality, which are two causes of death that are most responsive to environmental changes. The higher than average perinatal mortality in Glasgow reflects a socially deprived population, and the Royal Maternity Hospital serves a district with a high percentage of patients of low social class. We found that between 1971 and 1974 there had been no change in the pattern of social class distribution. There was no evidence, therefore, to suggest that population changes were sufficient to explain the improved results over the 10 years.

Induction of labour has not been the only change in management over the past 10 years, and standards of antenatal, intrapartum, and paediatric care have all improved. Our finding that the reduction in the number of deaths in the mature, unknown cause category was greatest in those occurring after term and before the onset of labour, indicates, however, that an active induction policy has made an important contribution to the fall in the number of these deaths. In the second five-year period there was a fall in the incidence of deaths due to trauma. Active management of labour and increased use of caesarean section may have contributed to this improvement, particularly in cases of cord accident and obstructed and prolonged labour.

Furthermore, there was no evidence that the higher induction rate had increased the number of deaths due to trauma or caused any deaths due to unsuspected prematurity. This evidence would suggest that the newer methods of obstetric care, of which induction of labour is an integral part, have been the major factors responsible for the improved results in the mature, unknown cause, group of deaths.

In a similar study to our own Chalmers $e t a l^{6}$ failed to show improvement in perinatal mortality among Cardiff residents over nine years during which time the induction rate rose from $7 \cdot 5 \%$ to $26.5 \%$. In their classification, however, they attributed up to $34 \%$ of their total perinatal deaths to "anoxia and birth injury." In 1954 Baird et $a l^{7}$ stated "It is not much help to know that the baby died of anoxia or prematurity and atelectasis unless the origin of these conditions is known." For this reason we used the Baird classification of perinatal deaths according to clinical 
cause. It would be interesting to know how many of the perinatal deaths in the "anoxic" group in Cardiff corresponded to deaths of unknown cause in mature infants and to know the age, parity, height, and social class of the mothers. Higher induction and section rates in these groups most at risk might have resulted in better figures.

Fedrick and Yudkin' reported a reduction in the number of stillbirths in the Oxford area associated with a rising induction rate. The reduction was more apparent in induced than in noninduced births. As they pointed out themselves, however, when the induction rate is low only pregnancies at very great risk are included in an induced group, but as the induction rate rises, more and more relatively normal cases are induced. It is difficult, therefore, to draw firm conclusions about the benefits of induced labour from their method of analysing their data. Possibly the optimum induction rate will vary from area to area depending on the characteristics of the populations. By detailed analysis of our population and classification of the causes of our perinatal deaths, we were able to show where greatest improvement could be made, and it would be valuable to compare our results with those from other centres. Our present findings strongly suggest that increased use of induction of labour has contributed to a reduction in perinatal mortality.

\section{References}

1 Walker, J, Fournal of Obstetrics and Gynaecology of the British Empire, 1954, $61,162$.

${ }^{2}$ Butler, N R, and Bonham, D G, Perinatal Mortality. Edinburgh, Livingstone, 1963.

3 Racker, D, Burgess, G H, and Manly, G, Lancet, 1953, 2, 953.

4 Theobald, G W, Lancet, 1959, 1, 59.

5 Baird, D, British Medical fournal, 1976, 1, 896.

6 Chalmers, I, et al, British Medical fournal, 1976, 1, 735.

7 Baird, D, Walker, J, and Thomson, A M, Fournal of Obstetrics and Gynaecology of the British Empire, 1954, 61, 433

${ }^{8}$ McIlwaine, G M, et al, Health Bulletin, 1974, 32, 1031.

${ }^{9}$ Fedrick, J, and Yudkin, P, British Medical fournal, 1976, 1, 738.

(Accepted 7 December 1976)

\title{
Congestive cardiomyopathy in uraemic patients on long term haemodialysis
}

\author{
TILMAN DRÜEKE, CLAUDE LE PAILLEUR, BRUNO MEILHAC, CONSTANTIN KOUTOUDIS, \\ JOHANNA ZINGRAFF, JEAN DI MATTEO, JEAN CROSNIER
}

British Medical fournal, 1977, 1, 350-353

\section{Summary}

Five uraemic patients who developed progressive cardiac failure with clinical evidence of congestive cardiomyopathy at the start or during haemodialysis treatment were studied. The diagnosis of cardiomyopathy, for which there was no apparent cause, was confirmed by angiocardiographic and haemodynamic studies. These showed a significant increase in left ventricular enddiastolic volume over normal values obtained in 12 patients without uraemia. The mean velocity of myocardial fibre shortening was significantly decreased, as was the index of normalised rigidity. Three of the five patients presented the complete picture of the disease. The other two also had considerable ventricular dilatation and a decreased index of normalised rigidity but normal ejection fraction and only moderately decreased myocardial contractility indices. This suggests that there may be primary involvement of normalised heart muscle rigidity followed by secondary changes in myocardial contractility in uraemic patients with congestive cardiomyopathy.

\footnotetext{
Départements de Thérapeutique Néphrologique and Clinique Cardiologique, Hôpital Necker, Université René Descartes, Paris TILMAN DRÜEKE, MD, physician CLAUDE LE PAILLEUR, MD, physician BRUNO MEILHAC, MD, physician CONSTANTIN KOUTOUDIS, MD, physician JOHANNA ZINGRAFF, MD, chargé de recherche INSERM JEAN DI MATTEO, MD, professor of cardiology JEAN CROSNIER, MD, professor of nephrology
}

\section{Introduction}

Cardiac failure remains one of the most important contributory causes of death in patients undergoing maintenance haemodialysis. ${ }^{12}$ Various factors are implicated in the pathogenesis of heart failure during chronic renal insufficiency-for example, coronary artery disease and hypertension, ${ }^{1}$ pericarditis, hypokalaemia or hyperkalaemia, disorders of calcium metabolism, and possibly anaemia, acidosis, and overhydration with hypervolaemia. $^{3}{ }^{4}$ The question remains whether a specifically "uraemic" cardiomyopathy, due to the retention of normally excreted or metabolised substances, may also be implicated. ${ }^{5}$.

In $1944 \mathrm{Raab}^{7}$ suggested that cardiotoxic substances may exist in the blood and heart muscle in uraemia, and recent experimental evidence has supported the suggestion that uraemia may have a direct effect on myocardial function. During acute renal failure in rats Nivatpumin et $a l^{8}$ observed increased contractility in the myocardium, whereas Riecker et $a l^{4}$ suggested that the contractile state of the acutely uraemic heart was diminished after adrenergic stimulation in the guineapig in vivo. In experimental chronic renal failure Hennemann et $a l^{9}$ reported an increased isometric contraction force of isolated rat atria but a decreased myocardial ${ }^{45} \mathrm{Ca}$ uptake after stimulation with the beta-adrenergic agonist, isoproterenol. Scheuer et $a l^{10}$ provided indirect evidence that uraemic serum had a net depressant effect on myocardial performance in chronically uraemic rats in vivo. They also demonstrated depressed cardiac function when normal rat hearts were perfused with mixtures of urea, creatinine, methyl guanidine, and guanidinosuccinic acid. ${ }^{11}$

In 1967 Bailey et al $^{12}$ described five patients with terminal renal insufficiency who developed severe heart failure that was reversed after intensive haemodialysis. Hypertension and anaemia seemed unlikely major causes of cardiac failure in these patients, and the authors suggested that uraemic "toxins" might be implicated. Recently Scheer et $a l^{13}$ and Rodger et al ${ }^{14}$ presented evidence that cardiomyopathy of unknown cause occurs 